\title{
Lectura, escritura, cultura académica y formación de docentes
}

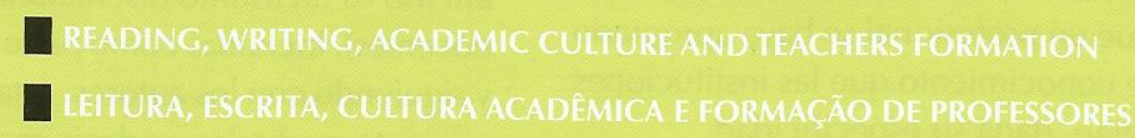

Nylza Offir García Vera' / nylzao@yahoo.es

El artículo plantea la relación intrínseca de los procesos de la lectura y escritura con la cultura académica, en el marco de la formación universitaria y específicamente de la formación de docentes. Asumidos estos dos procesos en su especificidad dentro de este marco discursivo, se propone a la vez una mirada a la manera como se piensan y se desarrollan en términos pedagógicos y didácticos en los espacios académicos dedicados a este tema.

This article explains the close relationship between reading and writing processes and, the academic culture within the framework of teacher's education. Once reading and writing are assumed as academic skills, it is proposed to have a look about how they are developed in pedagogical and didactical terms in the academic spaces devoted to this topic.

O artigo cria a relação intrínseca dos processos de leitura e escrita com a cultura acadêmica na universidade e, especificamente, a formação de professores. Com estes dois processos, na sua especificidade discursiva dentro deste quadro, propõe-se tanto uma olhada na maneira em que eles pensame desenvolver se em termos de educação e de ensino em espaços acadêmicos dedicados a este tema.

\section{Palabras clave}

Lectura, escritura, cultura académica, formación de docentes.
Reading, writing, academic culture, teachers' education.
Leitura, escrita, cultura acadêmica, formação de professores.

* Profesora Facultad de Educación. Universidad Pedagógica Nacional.

Candidata a Magíster en Pedagogía. Universidad Industrial de Santander. Especialista en Enseñanza del Español y la Literatura. Universidad de Pamplona. 


\section{A manera de prolegómenos ${ }^{1}$}

\section{La formación universitaria, independiente} del tipo de profesión y de las disciplinas que la conformen, implica siempre un proceso de formación en una cultura académica. Es decir, lo que se espera es que un profesional se haya apropiado de unas fuentes de conocimiento que las instituciones educativas privilegian, dada su especificidad.

Mockus et al (1997), en su trabajo "Las fronteras de la escuela", definen esta cultura académica -valga anotar, como idealización- en función de la imbricación de cuatro fuentes de conocimiento: la discusión racional, la tradición escrita, el cálculo y el diseño posibilitados por el uso de la escritura y otros procedimientos de representación simbólica; y la acción orientada y organizada racionalmente como en el caso de la experimentación científica. Sin embargo, aun cuando se privilegien unas $\mathrm{u}$ otras fuentes de conocimiento (aunque, según los autores, la integración de las mismas es lo que constituye en rigor la cultura académica) la experiencia o el conocimiento acumulado se traduce siempre en forma escrita y la deliberación o argumentación se da siempre en razón del reconocimiento de una tradición en un campo científico o disciplinar, que también está escrita o codificada alfabéticamente (Cfr. Mockus, et al. 1997, pp. 63-74).

De lo anterior, se colige que tanto la escritura (producción) como la lectura (interpretación) están en el eje estructurado y estructurante de la cultura académica. Podemos afirmar que son constituyentes en sí mismas de esta cultura, al tiempo que posibilitan su apropiación: "el alumno que frente a un problema de conocimiento cree que una discusión clarifica, el que para resolver ese problema busca un libro o se sienta a escribir, o el que dispone metódicamente los medios para llevar a cabo de manera racionalmente prefigurada una determinada acción" (p. 73); es la imagen que se

1 Las reflexiones iniciales del presente artículo tienen su base en las discusiones desarrolladas alrededor del tema con un equipo de profesores del área de la Facultad de Educación, en el marco de la construcción de un Núcleo Básico Común, NBC, en comprensión y producción de textos para los cuatro programas que ofrece el departamento de Psicopedagogía (Psicología y Pedagogía, Educación Especial, Educación Comunitaria y Educación Infantil). Bajo mi coordinación el equipo estuvo integrado por los profesores: Erika Maldonado, Gabriel Lara, Paola Fernández, Paula Marín, Lili Cañón, Maria Victoria Flórez, Constanza Pulido, Jennifer Ricaurte y Sandra Lucía Rojas. presenta para quien ha asimilado algunos de los cánones de la cultura académica.

La lectura y la escritura, como formas de expresión y de comprensión del código escrito, constituyen así las formas privilegiadas en la escuela y en la universidad, precisamente por el tipo de cultura que está en juego allí (no es un asunto discrecional o de capricho de los docentes). Incluidas como parte de la tradición letrada, y siguiendo con los autores, éstas son fuentes de conocimiento mediadas, es decir, requieren de procesos especializados y explícitos de transmisión y apropiación diferentes de las fuentes de conocimiento inmediatas, que aunque también provienen de un acervo cultural en el sujeto y ponen en juego la experiencia, la percepción y la imaginación, no requieren de un aplazamiento en la toma de posición o de la estructuración deliberada de actividades que medien entre una pregunta y su solución, como sucede en la cultura académica.

En la escuela y en la universidad circulan entonces unos textos, que en términos bajtinianos corresponden a géneros discursivos secundarios (cuya expresión pueden ser, entre otros, los textos académicos y de divulgación científica), y que distan de los géneros discursivos primarios, es decir, de aquellos que se usan en la cotidianidad y que están siempre mediados por el código oral (Cfr. Bajtín, 2002, pp. 248-293). El sociólogo Basil Bernstein (1993) también nos ofrece desde su corpus teórico una explicación de este tipo de conocimiento educativo que circula en estas agencias de socialización (las instituciones educativas) y que se corresponde con la exigencia de adquisición de lo que denomina los códigos elaborados. Dependientes siempre del contexto, estos códigos determinan los significados relevantes según sean las prácticas discursivas propias del nivel de la agencia. Así, las agencias educativas, dada su naturaleza, privilegian los códigos elaborados que, desde esta teoría, implican siempre unas bases semánticas (en términos de significados) más independientes del contexto, menos locales y con tendencias universalistas. En todo caso, la asunción de estos códigos supone de alguna manera una ruptura con las formas y los contenidos que se juegan precisamente en las narrativas orales y en los contextos particularistas y locales que se pueden corresponder con el concepto de los códigos restringidos 2 .

2 Valga anotar que es precisamente en el marco de esta teoría que Bersntein pone en evidencia que los logros diferenciales de niños 
En síntesis, la formación en la universidad requiere de la apropiación de una tradición, de unas disciplinas que aparecen siempre codificadas alfabéticamente $y$ son materializadas en forma de textos que hay que interpretar. Pero interpretar aquí es también producir nuevamente esos textos, construirles su sentido e incluso hacerles preguntas, hasta llegar a unos niveles de elaboración y de producción escritural. En su aspiración más alta, el proceso de construcción de conocimientos pasaría en la universidad por estas dos actividades hasta llegar a un proceso más estructurado y deliberado de producción de conocimiento, cuya expresión sería la investigación. El corolario de esta espiral es ineludible: no hay escritura sin lectura, no hay entonces investigación sin lectura y escritura. Así mismo, las formas de comunicación del conocimiento producido, circulan también como producto de estos tres procesos en forma de textos.

Situándonos en la especificidad de la formación profesional de un docente, esto quiere decir que los procesos de lectura y escritura en la universidad son actividades que median y estructuran la formación de la cultura académica de los futuros maestros y el acceso a los códigos de formación propios de sus disciplinas. Así mismo, son éstos quienes, a su vez, independientemente de su área de desempeño, tendrán que contribuir en las escuelas a la enseñanza de la lectura y la escritura de los niños y de los jóvenes, puesto que en un símil con la cultura académica, estos dos procesos constituyen también la piedra angular de la cultura escolar, al tiempo que median los procesos de aprendizaje y de construcción de conocimiento. Es por ello que esta reflexión se sitúa en torno a la lectura y la escritura en la universidad y en su significado dentro de la formación docente, pues no sobra advertir que difícilmente un maestro puede enseñar o desarrollar una competencia que no haya sido adquirida y desarrollada antes en él mismo.

procedentes de dos clases sociales (media y obrera) no radican en un problema de IQ hereditario o invariable, sino que está determinado por las relaciones sociales que actúan selectivamente sobre los principios o focos de la comunicación. En ese sentido, el concepto de código es inseparable de los conceptos de comunicaciones legítimas e ilegítimas según el tipo de agencia y las prácticas discursivas propias de la misma. Cfr. Bersntein B. Códigos elaborados y restringidos: revisión y crítica. En: La construcción social del discurso pedagógico. Bogotá, El Griot, 1993. pp. 81-115.

\section{Los presupuestos iniciales}

\section{Primer presupuesto}

En todas las carreras, sean éstas de formación docente o de formación en otras profesiones, es ya un hecho generalizado encontrar dentro del plan de estudios unos espacios académicos o asignaturas relacionadas con el tema de la lectura y la escritura. Las denominaciones de estos cursos son bastante diversas; para mencionar algunas, van desde Habilidades comunicativas, Expresión oral y escrita, Comunicación escrita, Lecto-escritura, Competencias lectoescriturales hasta otros más innovadores o más a tono con las tendencias en el área: "Producción y comprensión de textos", o "Competencias comunicativas", entre otros. No obstante esta diversidad de denominaciones, usualmente estos espacios surgen como respuesta a una misma problemática: la capacidad lectora y escritural de los estudiantes que ingresan a la Universidad. Esta fuente de preocupaciones es compartida no sólo por los profesores de las carreras de licenciatura, sino por el conjunto de carreras profesionales en las diferentes universidades públicas y privadas del país.

Lo cierto es que parece sintomático que se coincida en un mismo problema y que se ponga en evidencia cuando, casi en un clamor, los profesores universitarios insisten en que los estudiantes "no saben leer y escribir" "no saben poner una coma", "no entienden lo que leen", "no quieren leer"; y la tendencia es siempre a volver la mirada hacia los profesores de educación básica y media, éstos a su vez miran en especial a los profesores de los primeros grados, pues "fueron ellos los que les enseñaron a leer" 3 , y para ampliar el círculo se empiezan a buscar las causas en los factores de orden cultural; aparecen entonces en la escena la familia y el entorno social. Entre tanto, algunos empiezan a sospechar que el asunto es un problema estructural de nuestro sistema educativo y como este es parte de una sociedad, el corolario en inevitable: es el problema de todo un país y de su tradición letrada.

3 A su vez, en la universidad es frecuente que la mirada recaiga, como en la escuela, en los profesores que trabajamos estos espacios académicos. 


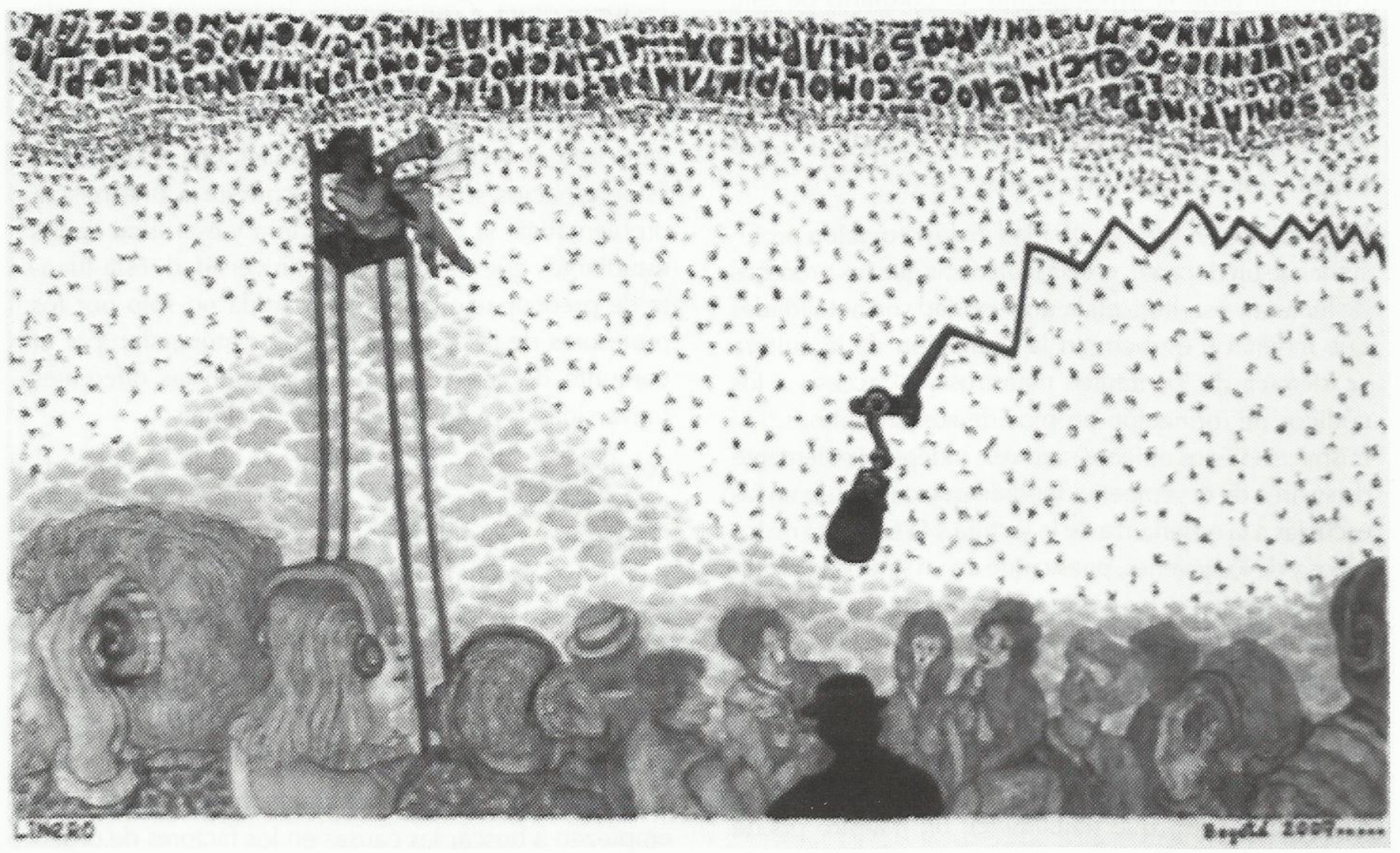

Guillermo Linero Montes \Sin título >P Plumilla y acuarela $35 \times 45 \mathrm{~cm}$ 
Cuando los estudiantes Ilegan a la universidad, partimos siempre de la base de que ya saben leer y escribir, no sólo en el sentido de la decodificación, sino en el sentido de su competencia para interpretar y producir diferentes textos, pues ya han pasado por la escuela, ya han apropiado la cultura escolar que supone de base estas dos competencias. Sin embargo, esto no siempre es así, de un lado, porque la cultura escolar es siempre distinta de quienes la agencian (los maestros) o de quienes la apropian (los alumnos); 4 y, de otro lado, porque aun cuando los estudiantes hayan logrado suficientes niveles de competencia en lectura y escritura, de todas maneras los textos que circulan en la academia corresponden a otro nivel de producción de discurso y a formas textuales que no son siempre consecuentes con los que han circulado en la escuela básica y media 5 .

En los textos académicos universitarios predomina la exposición y la argumentación, y sus estructuras discursivas suponen altos niveles de abstracción. Además, no se usan sólo para transmitir, informar o dar cuenta de éstos, sino para desarrollar procesos de apropiación y construcción de conocimiento y para generar algunas elaboraciones a partir de los mismos. Es decir, se demandan procesos de interpretación (en los más altos niveles de inferencia, abstracción, intertextualidad y distanciamiento crítico) y de producción (a manera de síntesis, de análisis, de valoración, de crítica y de exposición o argumentación de un punto de vista). Ello supone unas especificidades al abordar los textos especializados de las disciplinas: desde comprender las macro y superestructuras, las formas de discurso, las intencionalidades y las tesis que comportan, hasta identificar y explicar las perspectivas teóricas que están en juego, bien sea para contrastarlas, para asumirlas o para ir construyendo sus propias tesis.

De esta manera, los procesos de lectura y de escritura en la formación profesional adquieren una especificidad

4 Puede ocurrir que alguien haya pasado por la escuela y, sin embargo, no apropie la cultura escolar o lo contrario, alguien que no ha ido a la escuela $y$, sin embargo, ha apropiado su cultura, que implica no sólo saber decodificar sino desarrollarse como lector y como escritor. Recordemos el caso de Estanislao Zuleta, quien se retiró del colegio porque las tareas no le dejaba tiempo para leer y para escribir. Aquí el asunto no es entonces por insuficiencia sino por suficiencia en la adquisición de la cultura letrada.

5 Esto último corresponde grosso modo con la tesis central de Paula Cerlino (2005). ligada a los contextos discursivos en los que son demandados y a los propósitos mismos de tales demandas y difieren entonces no sólo de las prácticas escolares anteriores a este tipo de formación, sino también a otras prácticas y usos sociales por fuera de la academia.

\section{La lectura, el texto y el proceso de interpretación}

Muchas teorías en torno a la lectura, sean éstas de orientación hacia el texto o hacia el lector, coinciden en situar el problema de la comprensión-interpretación en el acumulado sociocultural del sujeto. Desde la psicolingüística, Smith (2001) planteará el problema desde la distinción entre información visual e información no visual. La primera corresponde a lo que se nos presenta "a través de los ojos" (el texto escrito) y la segunda, a lo que hay "detrás de los ojos", es decir, el conocimiento acumulado tanto del lenguaje mismo como de la materia objeto de interpretación (estructura cognoscitiva-teoría de mundo). Para el autor, el asunto de la comprensión se entiende en síntesis así: "entre más información no visual tenga un lector, menos información visual necesita" (Smith, 2001, p. 17).

Desde la semiótica, y específicamente desde el corpus explicativo de Umberto Eco (1987), el texto escrito, "tal como aparece en su superficie (o manifestación) lingüística, representa una cadena de artificios expresivos que el destinatario debe actualizar" (Eco, 1987, p. 73). La actualización, según el autor, requiere ciertos movimientos cooperativos, activos y conscientes por parte del lector (destinatario). Actualizar es, entre otras cosas, activar la enciclopedia cultural que permite rellenar los intersticios que deja el texto, puesto que en la superficie no está dicho todo, es precisamente lo no manifiesto en el plano de la expresión, o lo "no dicho", lo que debe explicitarse en la etapa de la actualización del contenido. La enciclopedia corresponde aquí no sólo a la competencia en la lengua, sino también al patrimonio social que esa lengua ha creado: "a saber, las convenciones culturales que esa lengua ha producido y la historia misma de las interpretaciones previas de muchos textos, incluyendo el texto que el lector está leyendo" (Eco, 1992, pp. 72-73). Finalmente, para este autor todo acto de lectura es básicamente una "difícil transacción" entre la competencia del lector (su conocimiento del mundo) y la clase de competencia que 
determinado texto postula con el fin de ser leído de modo económico. 6

Pero es quizás Louis Rosenblatt (1988) quién más ha enfatizado en el lugar central que ocupa el lector en el proceso de interpretación de un texto y en las implicaciones pedagógicas derivadas de este acontecimiento. Acudiendo a la naturaleza social y transaccional del lenguaje, y situando su teoría en un marco más amplio, desde la filosofía, la psicología, la literatura y la semiótica, afirma:

Cada acto de lectura es un evento, una transacción que envuelve un lector particular y una configuración particular de marcas en una página, y ocurre en un tiempo particular y en un contexto particular. Ciertos estados del organismo, ciertos rangos de sentimiento, ciertos nexos simbólicos $o$ verbales, son activados en nuestro reservorio lingüístico. [...] El significado no reside ya hecho en el texto o en el lector, sino que ocurre durante la transacción entre lector y texto (p. 6)7.

En su ya reconocida teoría transaccional, la autora define dos tipos de posicionamientos del lector frente al texto. Una posición eferente en la que predomina el significado público del texto y una posición estética en la que predomina el significado privado del mismo. En la metáfora del iceberg, la punta corresponde al significado público del texto y la base al significado privado. En ese sentido, anota:

\section{Cualquier actividad lingüística tiene tanto el com- ponente público (lexical, analítico y abstracto) como el componente privado (experiencial, afec- tivo y asociacional). La posición-del lector-está determinada por la proporción de cada uno ad- mitida dentro del espectro de atención selectiva. La posición eferente se basa principalmente en el aspecto público del sentido. La posición esté- tica incluye proporcionalmente más del aspecto privado experiencial (p. 8).}

Sin embargo, ambas posiciones son inherentes al acto de lectura en la medida en que conforman para la autora un continuum eferente/estético de sentido.

Finalmente, la hermenéutica de Gadamer nos ofrece también una perspectiva para pensar el problema de

6 Se trata aquí de la posible configuración de lector modelo para Eco.

7 Versión libre del inglés por Nylza Offir García Vera. la comprensión de los textos. En su explicación de la experiencia hermenéutica, como condición ontológica del sujeto, la "conversación" con un texto supone que éste sólo pueda llegar a hablar a través de la otra parte, es decir, del intérprete: "el texto hace hablar a un tema, pero quien lo logra es en último extremo el rendimiento del intérprete. En esto tienen parte los dos" (Gadamer, 1996, p. 466). La comprensión e interpretación de los textos, tarea hermenéutica por excelencia, se corresponde en este autor con una fusión de horizonte de sentido. No es un asunto en el que prime la subjetividad del lector o del autor, puesto que precisamente la escritura como fenómeno hermenéutico permite hacer una ruptura con estos sujetos concretos: la comprensión no es una transposición psíquica, nos recuerda Gadamer.

La comprensión -en este caso el autor la refiere tanto a la tradición literaria como a la historia-implica aquí que "lo que se dice en el texto tiene que ser despojado de toda contingencia que le sea inherente, y entendido en la plena idealidad en la que únicamente tiene su valor" (p. 477). No obstante, tal idealidad y valor de sentido no implica despojarse de los conceptos previos y los prejuicios del propio tiempo, sino más bien tener plena conciencia de ellos: "Interpretar significa justamente aportar los propios conceptos previos con el fin de que la referencia del texto se haga realmente lenguaje para nosotros" (p. 477).

Estas perspectivas brevemente referidas, desde autores, disciplinas y momentos históricos distintos, intentan abrir el panorama de la discusión en torno al tema de la comprensión e interpretación de los textos que se ponen a circular en la academia y el lugar del acumulado sociocultural del estudiante (en tanto lector) en estos procesos. No se trata entonces de enseñar la lectura como una técnica aislada que resuelva el problema de la comprensión de los textos académicos. Se trata más bien de entender que si los conceptos previos, la visión de mundo, los intereses, las emociones, los afectos, los saberes y el conocimiento sobre el propio lenguaje escrito, están implicados en la construcción del sentido de estos textos, de lo que se trata aquí es de pensar las condiciones de posibilidad que en términos pedagógicos tenemos para ampliar este conjunto experiencial de los estudiantes (en inglés, la palabra background puede definir de manera general los aspectos enunciados) para ampliar las posibilidades de comprensión de los textos y de los discursos propios de las disciplinas y de los campos de desarrollo profesional 
de los futuros maestros. Entre otras cosas, esto quiere decir que no se resuelve sólo con un espacio académico que propicie la reflexión en torno a la lectura como objeto de conocimiento y como actividad estructurante de la cultura académica, sino que implica al conjunto de todos aquellos que la agencian.

Retomando a Gadamer, valga anotar finalmente que la interpretación no es un medio para producir la comprensión, sino que se introduce por sí misma en el contenido de lo que se comprende. La interpretación es siempre entonces apropiación de lo dicho, de tal forma que se convierta en cosa propia, anota el autor. El texto toma entonces la palabra en el lector, en tanto la interpretación coloca el tema en la balanza de las palabras (p. 478). ¿Y no es precisamente esto lo que enunciamos como parte de nuestros propósitos formativos en los diferentes espacios académicos? ¿Y no es también lo que indagamos en los modos de evaluar a los estudiantes? Que comprendan, que se apropien, y que produzcan unos discursos.

\section{La escritura, y el proceso de producción textual}

Podemos anotar con Ricouer (2006) que "la escritura es la manifestación íntegra del discurso". No sólo se trata de un ejercicio de su fijación en aras de preservarlo, sino que al quedar fijado en la escritura el discurso está afectado en su función comunicativa. Para este autor, la escritura "es el pensamiento humano directamente puesto por escrito sin la etapa intermedia del lenguaje hablado" (Ricouer, 2006, p. 38). La escritura se perfila de esta manera como una actividad de orden cognitivo, comunicativo, discursivo y textual.

En primera instancia, la implicación cognitiva que supone la adquisición de la escritura como sistema de significación en el marco de la cultura escolar es referida directamente por Walter Ong, para quien: Sin la escritura el pensamiento escolarizado no pensaría ni podría pensar cómo lo hace, no sólo cuando está ocupado en escribir, sino incluso normalmente cuando articula sus pensamientos de manera oral. Más que cualquier otra invención particular, anota el autor, la escritura ha transformado la conciencia humana" (Ong, 1994, p. 8). En la medida en que la escritura está mediada por condiciones espaciales y temporales que difieren de un contexto comunicativo próximo o inmediato, esta "tecnología de la palabra" obliga al sujeto al distanciamiento, toda vez que el discurso escrito requiere autonomía del contexto y exige condiciones mínimas para ser leído, esto es, exige cierta universalidad8.

Sin embargo, no es suficiente con adquirir el sistema. Tolchinsky (1993), haciendo referencia precisamente a varias investigaciones sobre esta influencia de la alfabetización en la estructura cognitiva de los sujetos, afirma que lo que desarrolla el intelecto no es sólo la escritura en sí misma sino su uso en una multiplicidad de funciones, en tanto "La escritura afecta nuestra manera de pensar en los procesos de lectura, en la interpretación, en la discusión y en la producción de textos" (Tolchinsky, 1993, p.70). Las funciones se refieren aquí a las formas de discurso que circulan en las comunidades y que cumplen diferentes propósitos. En la reflexión que nos convoca, las comunidades académicas privilegian propósitos expositivos y argumentativos, lo que supone que los procesos de producción textual promueven e implican a la vez formas superiores de pensamiento.

Así, y en segunda instancia, las implicaciones no sólo cognitivas, sino también comunicativas, discursivas y textuales de la escritura son derivadas de las condiciones pragmáticas de la comunicación que en este caso impone la academia. Es esto en rigor lo que define, por ejemplo, el privilegio de formas de argumentación razonada en la escritura, en los que la producción escritural exigida a los estudiantes no es otra cosa que un pretexto para poner en escena el discurso, para saber qué tanto se sabe, qué no se sabe y qué tanto está por saberse sobre un determinado objeto de conocimiento. Es en este proceso escritural en tanto producción de discurso en el que opera lo que Jurado (1992) denomina una tensión entre el pensamiento y su intento por hallar una forma de contenido: "La escritura obliga al sujeto a evaluar y revisar permanentemente sus propios dominios cognitivos, pone en crisis las ideas y parece empujar el texto hacia otros textos, hacia otras voces" (Jurado, 1996, p. 8).

Es por ello que la escritura oscila entre el leer otros textos y escribir, entre releer lo escrito y reescribir, donde

8 Estas consecuencias cognitivas de la alfabetización están documentadas en otros trabajos que han incidido directamente en la pedagogía y que permiten ubicar su adquisición y su uso con formas de pensamiento superiores. Cf. L. S. Vygotski. El desarrollo de los procesos psicológicos superiores. Barcelona: Crítica, 1995. 
emerge necesariamente la categoría de "proceso"9. Finalmente, Zuleta vincula la lectura con la escritura y ubica ésta última en el territorio de la búsqueda, de la incógnita abierta que guía el pensamiento y anota que "sólo se puede leer desde una escritura y que sólo el que escribe realmente lee" (Zuleta, 1995, p. 37).

\section{Lectura, escritura y argumentación}

La argumentación en la cultura académica constituye una condición inherente de la misma, pues la producción discursiva aquí exige un acto de razonamiento en el que los individuos se hacen responsables de su discurso en una situación específica de enunciación. En este marco comunicativo estamos entonces ante un propósito específico: acrecentar la adhesión a un punto de vista argumentado que se somete a la consideración de un auditorio. En estos casos no se trata de premisas que se discuten a favor de lo verdadero sino a favor de lo razonable. Ello implica para el sujeto de enunciación ofrecer razones y pruebas y no solamente exponer opiniones, prejuicios o creencias.

Y es precisamente la escritura un modo de verter este discurso argumentado, cuya forma de razonamiento implica, entre otras cosas, pasar del juicio inmediato a la suspensión del mismo, poner en cuestión las certezas, identificar y reconocer la suficiencia o insuficiencia de unos argumentos (los propios y los de otros sujetos) y problematizar los conceptos; todo ello en el marco de un desarrollo discursivo que supone estructuras explicativas y argumentativas que den cuenta de la complejidad del objeto de conocimiento abordado.

Silvestre (2001) identifica en el dominio de las habilidades comprensivas y productivas la posibilidad de configurar la competencia argumentativa del sujeto. Para la autora, no es asunto sólo del desarrollo de habilidades comunicativas, sino que funciona también como formas de representación mental que traducen procedimientos conceptuales del sujeto. Al concebir la argumentación en esta perspectiva estamos situando su desarrollo en función no sólo de la comunicación sino también de la cognición en un ámbito sociocultural concreto, la

9 En algunos estudios sobre la escritura, los borradores constituyen, por ejemplo, una importante fase en el conjunto de la producción de los escritores expertos, que implica además, la planificación del texto a producir, la corrección en distintos niveles de la estructura del texto y la edición (Cfr. Cassany, 1999). formación profesional universitaria, siendo también aquí una condición de posibilidad para la emergencia del pensamiento crítico: "la habilidad para producir una argumentación adecuada involucra el dominio de estrategias verbales que harán posible un despliegue convincente de las ideas o creencias en conflicto. En cuanto a las habilidades de comprensión, el conocimiento de los mecanismos argumentativos permite a los destinatarios una actitud crítica ante la manipulación a la que tienden gran número de discursos sociales y persuasivos" (Silvestre, 2001, p. 31).

En la universidad, los artículos científicos, las reseñas, los libros, las teorías, las investigaciones, en general los textos que se ponen a circular emergen siempre en un marco de argumentación razonada escrita. A su vez, las actividades de escritura propuestas a los estudiantes cuando se les pide resumir, reseñar o ensayar, implican también un ejercicio explícito de argumentación, reglado por sus propias estrategias textuales y por sus propios modos de producción discursiva. Ello supone la apropiación por parte del estudiante de una tradición y, por lo tanto, de un acumulado a través de la asunción y el desarrollo de procesos de lectura (en tanto comprensión y apropiación de discursos o interpelación de los mismos) y de escritura (en tanto producción que permite explicar, argumentar o contrargumentar)10. Toda argumentación académica es, pues, en este sentido, el producto del desarrollo de estos procesos de comprensión y apropiación y sugieren que el nuevo discurso que se produce es siempre por su naturaleza de carácter polifónico y dialógico (Bajtín, 2002).

No obstante, muchas veces la complejidad del proceso mismo de escribir y de argumentar se acentúa por las formas y demandas propias que se le hacen al estudiante. La idea de "proceso" escritural y de argumentación razonada implica unos tiempos para profundizar en un tema, hacerse preguntas, problematizar lo escrito, entre otros pasos, lo cual se aleja de la tendencia a exigir muchos textos, algunos de los cuales por efectos del tiempo otorgado a los maestros para planificar y acompañar estos procesos, se quedan sin la adecuada

10 No obstante, la argumentación razonada en tanto género complejo además de tener como condición el desarrollo de procesos de comprensión y de producción discursivos-textuales, tiene como exigencia el desarrollo de más condiciones de orden cognitivo en el sujeto: el razonamiento formal, la complejidad representacional, la especificidad de dominio y la competencia discursiva. Para ampliar: (Silvestre, 2001, pp. 29-47). 
interlocución, lo cual es una condición inherente a la escritura, toda vez que indefectiblemente escribimos siempre para otros.

\section{Una reflexión final y una investigación pendiente}

Sin abstraernos de la incidencia de los elementos sociales y culturales, y por supuesto de las condiciones materiales para acceder a la lectura y a la escritura, que sabemos, determinan en gran medida el desarrollo y la cualificación de estos procesos en los estudiantes en formación, en nuestro caso, los futuros maestros, es preciso también empezar a indagar por lo que sucede en términos pedagógicos y didácticos en los espacios académicos (asignaturas) dedicados a este tema. Esta es una preocupación compartida no sólo por los profesores de esta área en el marco de los procesos de formación docente -que por demás complejiza el problema, en tanto dicha profesión exige la apropiación y el desarrollo de la cultura académica, dada su naturaleza intelectual- sino también por el conjunto de profesores que forman profesionales de otras áreas y disciplinas.

Como producto de estas preocupaciones, ha surgido precisamente una hipótesis de trabajo que constituye la base de un proyecto de investigación agenciado por diez y siete universidades del país, dentro de las cuales se encuentra la Universidad Pedagógica Nacional11. En ésta hipótesis se plantea la siguiente situación:

La universidad promueve ciertos modos de leer y escribir, ciertas prácticas de lectura y escritura, en atención a un tipo de cultura académica que intenta favorecer. Detrás de dichas prácticas es posible leer la idea de cultura académica que circula en nuestro país. Esas prácticas, además de estar determinadas por las capacidades lectoras y escritoras de los estudiantes, por sus características socioculturales y sus trayectorias académicas, están marcadas de modo fuerte por las prácticas académicas de lectura y escritura que se propician en la formación universitaria (PUJ, 2008, p. 25).

En esa perspectiva nos preguntamos entonces: ¿Cuáles son las características y las condiciones de posibilidad de las prácticas académicas de lectura y escritura en la universidad colombiana? ¿Cuáles de estas prácticas son valoradas positivamente por los estudiantes? ¿Cómo se explica la presencia de esas prácticas en algunos contextos universitarios? (p. 25).

Estos interrogantes incluyen, en relación con las prácticas de enseñanza, otros como los siguientes: ¿qué se pide leer al estudiante?, ¿para qué se pide leer y escribir?, ¿qué se hace con lo que se lee y se escribe?, ¿cuáles son los mecanismos de legitimación, valoración y evaluación de los productos de lectura y escritura en la universidad?, ¿qué clase de apoyos reciben los estudiantes antes, durante y después de la lectura y escritura de textos? (p. 25).

No está por demás decir que las condiciones pedagógicas están, así mismo, influidas por las condiciones laborales de los profesores que agencian este tipo de formación en las universidades, pero también por la manera como cada uno vincula su actividad intelectual con la lectura y la escritura. Leer y escribir, además de mediar las prácticas discursivas propias de la academia tales como la investigación y la divulgación científica en la universidad, inciden también en la producción intelectual del profesor y en sus procesos de enseñanza.

11 El proyecto se denomina ¿Para qué se lee y se escribe en la universidad colombiana? Un aporte a la consolidación de la cultura académica del país. Financiado por Colciencias con código PREOO439015708 y coordinado por la Pontificia Universidad Javeriana, en convenio con las universidades del Atlántico, de la Amazonia, de Antioquia, Autónoma de Occidente, Católica Popular del Risaralda, del Cauca, de Córdoba, de Ibagué, del Pacífico, del Quindío, del Valle, Caldas, Javeriana-Cali, Fundación Universitaria Monserrate, Universidad Central Valle del Cauca y Universidad Pedagógica Nacional. 
Bajtin, M. (2003). El problema de los géneros discursivos. En: Estética de la creación verbal. Argentina: Siglo XXI Editores.

Bersntein, B. (1993). Códigos elaborados y restringidos: revisión y crítica. En: La construcción social del discurso pedagógico. Bogotá, El Griot.

Carlino, P. (2005). Escribir, leer y aprender en la universidad. Una introducción a la alfabetización académica. Argentina: Fondo de Cultura Económica.

Cassany, D. (1999). Describir el escribir. Cómo se aprende a escribir. España: Paidós.

Eco, U. (1987). Lector in fábula. Barcelona: Lumen.

Eco, U. (1992). Entre el autor y el texto. En: Interpretación y sobreinterpretación. Gran Bretaña, Cambridge University Press.

Gadamer, H. G. (1996). Verdad y Método. Fundamentos de una hermenéutica filosófica. Salamanca: Sígueme.

Jurado V., F. (1996). La escritura proceso semiótico reestructurador de la conciencia. En: Los procesos de la escritura. Jurado V., F. y Bustamante Z., G. (comps). Bogota: Magisterio.

Mockus, Hernández, Granés, Charúm, Castro. (1997). Las fronteras de la escuela. Bogotá: Magisterio.

Ong, W. (1994). Oralidad y escritura. México: Fondo de Cultura Económica.
Pontificia Universidad Javeriana. (2008). Proyecto: ¿Para qué se lee y se escribe en la universidad colombiana? Un aporte a la consolidación de la cultura académica del país. Radicado en Colciencias con código PREOO439015708. En: http//www. javeriana.edu.co/facultades/educación/09/grupos-pedagogiaslectura-escritura/investigaciones/index/

Ricoeur, P. (2006). Teoría de la interpretación. Discurso y excedente de sentido. México: Siglo XXI Editores.

Rosenblatt, L. M. (1988). (January). Writing and reading: The transactional Theory. Recuperado de: www.nwp.org/cs/public/ print/nwpr/599-9k. 11 de febrero de 2008.

Silvestre, A. (2001). Dificultades en la producción de la argumentación razonada en el adolescente: las falacias del aprendizaje. En: Aprendizaje de la argumentación razonada. Cali, Cátedra UNESCO y Universidad del Valle.

Smith, F. (2001). Comprensión de la lectura. México: Trillas.

Tolchinsky, L. (1993). Aprendizaje del lenguaje escrito. Barcelona: Anthropos.

Zuleta, E. (1995). Conferencia sobre la lectura. En: Los procesos de la lectura. Jurado V. F. y Bustamante Z. G. (comps). Bogota: Magisterio, 1995, p. 37. 


\section{Diálogo del conocimiento}

Constituir una auténtica cultura académica, una cultura universitaria a través de los procesos de lectura y escritura, es la apuesta que la profesora Nilza Offir García hace en su texto. Para el caso particular de la Universidad Pedagógica Nacional, es un llamado también a preguntarnos por el nivel de escritura y de lectura del maestro en formación, donde pone de manifiesto reflexiones construidas en torno al trabajo colectivo adelantado por maestros de la universidad.

El texto nos muestra a su vez dos presupuestos. El primero es pertinente en la medida en que hace visible una problemática real a la que nos afrontamos no sólo los maestros de universidad, sino también los maestros de educación media y pone de manifiesto interrogantes, tensiones que se dan en la práctica de los docentes en torno a las falencias de los estudiantes en los procesos de lectura y escritura. En un segundo presupuesto se muestra una acertada diferenciación entre los procesos de lectura y escritura en los niveles de básica y media con los que se dan en la universidad, diferenciando claramente el escenario universitario de los niveles básico y medio de educación. En este sentido valdría la pena preguntarnos entonces: ¿Qué se lee y escribe en los niveles de básica y media? ¿Cuáles son las diferencias de los procesos de lectura y escritura que se dan entre los niveles educativos?

El artículo del mismo modo nos señala la complejidad en el ejercicio escritural, que se manifiesta en la producción textual. Se da cuenta de la escritura en tanto corriente, fluido, devenir a decir de Deleuze: Escribir indudablemente no es imponer una forma (de expresión) a una materia vivida... Escribir es un asunto de devenir, siempre inacabado, siempre en curso y que desborda cualquier materia vivible o vivida, en términos de la autora es una escritura para volvernos a leer. Asimismo, ante dicha complejidad el escrito nos muestra acertadamente que es necesario la adecuación de tiempos para poder llevar a cabo un auténtico proceso. Al respecto nos invita a reflexionar sobre los tiempos reales del maestro para poder adelantar dicho proceso en momentos en los cuales sus cargas laborales cada vez son más extensas al igual que el número de estudiantes, aspectos que hacen parte de las políticas educativas que se han implantado en los últimos años en las universidades públicas colombianas

La lectura y la escritura están directamente relacionadas con la investigación, en este sentido y para finalizar, la profesora Nilza Offir García, deja abierto el texto a través de interesantes interrogantes que parten de una propuesta investigativa que se esta desarrollando con otras universidades del país, buscando de esta manera nuevos escenarios de investigación y reflexión en torno a la constitución de cultura académica a través de las prácticas de lectura y escritura en nuestras universidades, no sin antes invitar al maestro a una reflexión en torno a su producción intelectual como parte fundamental de su práctica profesional.

Víctor Manuel Rodríguez Murcia 